\title{
An Effective Cable Sizing Procedure Model for Industries and Commerial Buildings
}

\author{
M. Pratap Nair*, K. Nithiyananthan ${ }^{+}$ \\ * Faculty of Engineering and Computer Technology, AIMST University Bedong, Kedah, Malaysia \\ ${ }^{+}$Department of Electrical and Electronics Engineering, Karpagam College of Engineering, Coimbatore, \\ India
}

\begin{tabular}{l} 
Article Info \\
\hline Article history: \\
Received Jul 19, 2015 \\
Revised Oct 30, 2015 \\
Accepted Nov 12, 2015 \\
\hline
\end{tabular}

Keyword:

Ampacity

Cable sizing

Conductor

Current carrying capacity

Voltage drop

\begin{abstract}
This paper mainly focuses on the cable sizing methods and calculation of electrical cables according to the various international standards. For instance, International Electrotechnical Commission (IEC), National Electrical Code (NEC), British Standard (BS) and Institute of Electrical and Electronics Engineers (IEEE). The basic philosophy underlying any cable sizing calculations are the same. The main objective of this research work is to develop effective cable sizing model for building services.
\end{abstract}

Copyright (c) 2016 Institute of Advanced Engineering and Science. All rights reserved.

\section{Corresponding Author:}

K. Nithiyananthan, Department of Electrical and Electronics Engineering, Karpagam College of Engineering, Coimbatore, India Email: nithiieee@yahoo.co.in

\section{INTRODUCTION}

There are four primary reasons that the cable sizing is very important at design stage. First and foremost, cable sizing is important to function endlessly under full load condition exclusive of being damaged. Moreover, it is necessary to hold up the worst short circuit current flow and ensure that the protective devices are effective during an earth fault. Ensure that, the supply to the load with a suitable voltage and avoid excessive voltage drops.

\section{CABLE SELECTION, SIZING AND OTHER PARAMETERS}

Sizing Cable sizing methods follow the unchanged basic step process. Firstly, it's vital to gather data about the cables, installation surroundings, and the load that it will carry. In addition, it's crucial to find the current carrying capacity (A, ampere) and voltage drop per ampere meter $(\mathrm{mV} / \mathrm{A} / \mathrm{m})$ of the cable [1]. The current carrying capacity of a cable is the maximum current that can flow continuously through a cable without damaging the cable's insulation and other components [2]. Short circuit temperature rise and earth fault loop impedance are significant factors to verify the cable size.

Each conductors and cables except superconductor have some amount of resistance. This resistance is directly proportional to the length and inversely proportional to the diameter of the conductor.

$\mathrm{R} \alpha \mathrm{L} / \mathrm{a} \quad[$ Laws of resistance $\mathrm{R}=\rho(\mathrm{L} / \mathrm{a})]$ 
Voltage drop occurs in every conductor as the current flows through it. According to Institute of Electrical and Electronics Engineers (IEEE) rule B-23, at any point between a power supply terminal and installation, voltage drop should not increase above $2.5 \%$ of provided (supply) voltage [3].

The cable should withstand the temperature and heat emmisionwith using good insulation materials such as conductors, and bedding. Table 1 shows the current carried by any conductor for continuous periods during normal operation shall be such that the suitable temperature limits.

Table 1. Maximum operating temperatures for types of cable insulation

\begin{tabular}{ll}
\hline Type of insulation & Temperature limit \\
\hline Thermoplastic & $70^{\circ} \mathrm{C}$ at the conductor \\
Thermosetting & $90^{\circ} \mathrm{C}$ at the conductor \\
Mineral & $70^{\circ} \mathrm{C}$ at the sheath and more \\
\hline
\end{tabular}

Cables with larger cross-sectional areas have minor resistive losses. Bigger cable able to dissipate the heat better than smaller one. Hence a $15 \mathrm{~mm}^{2}$ cable will have a higher current carrying capacity than a 4 $\mathrm{mm}^{2}$ cable. Table 2 explains the difference between current carrying capacity of $16 \mathrm{~mm}^{2}$ and $25 \mathrm{~mm}^{2}$.

Table 2. Current carrying capacity and voltage drop of different types of cable size [4]

\begin{tabular}{ccc}
\hline Cable size & Current-carrying capacity & Voltage drop \\
\hline$\leq 16 \mathrm{~mm}^{2}$ & 0.95 & 1.10 \\
$\geq 25 \mathrm{~mm}^{2}$ & 0.97 & 1.06 \\
\hline
\end{tabular}

\section{Type of Cable}

Select suitable cable type
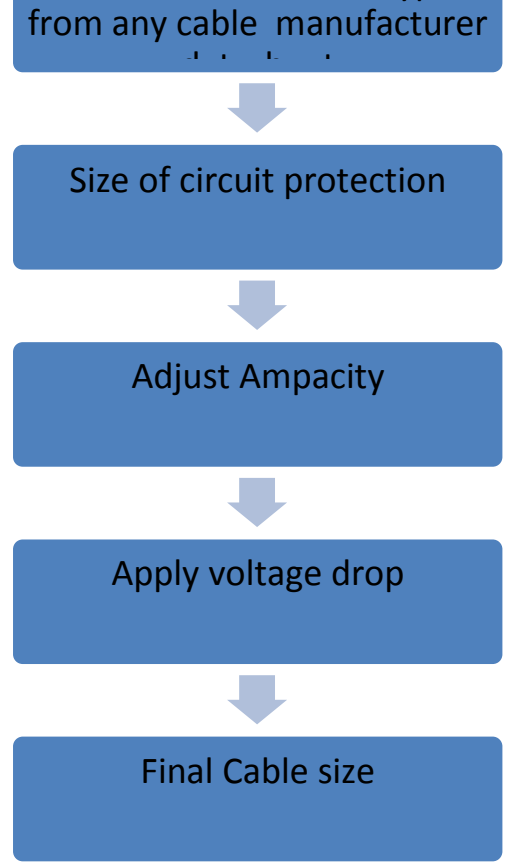

Figure 1. Flow chart shows the steps to determine the cable sizing and voltage drop 


\section{CABLE SELECTION SIZING FORMULAION}

International standards and cable manufacturers will provide derating factors for a range of installation conditions, for example ambientor soil temperature, grouping or bunching of cables, and soil thermal resistivity. The installed current rating is calculated by multiplying the base current rating with each of the derating factors.

$$
\mathrm{I}_{\mathrm{c}}=\mathrm{I}_{\mathrm{b}} \times \mathrm{k}_{\mathrm{d}}
$$

Where $I_{c}$ is the installed current rating $(A), I_{b}$ is the base current rating $(A)$ and $K_{d}$ are the product of all the derating factors.

Upstream protective device circuit breaker is not required to protect the cable against overloads. As a result, cables need only to be sized to cater for the full load current of the motor [5].

$$
\mathrm{I}_{1} \leq \mathrm{I}_{\mathrm{c}}
$$

Where $I_{1}$ is the full load current (A), $I_{p}$ is the protective device rating (A) $I_{c}$ is the installed cable current rating (A).

Cable Impedances is a function of the cable size (cross-sectional area) and the length of the cable. Most cable manufacturers will quote a cable's resistance and reactance in $\Omega / \mathrm{km}$. The following typical cable impedances for low voltage AC single core and multicore cables can be used in the absence of any other data [6].

\section{For single circuit}

$$
I_{t} \geq \frac{I_{n}}{C_{a} C_{s} C_{d} C_{i} C_{f} C_{c}}
$$

Where the protective device is is a semi enclosed fuse to $\mathrm{BS} 3036, \mathrm{C}_{\mathrm{f}}=0.725$ otherwise $\mathrm{C}_{\mathrm{f}}=1$. The cable installation method is 'in a duct in the ground' or 'buried direct', $\mathrm{C}_{c}=0.9$. For cables installed above ground $\mathrm{C}_{\mathrm{c}}=1 . \mathrm{C}_{\mathrm{a}}=$ Ambient temperature, $\mathrm{C}_{\mathrm{s}}=$ Soil resistivity, $\mathrm{C}_{\mathrm{d}}=$ dept of burial, $\mathrm{Ci}=$ Thermal Insulation, $\mathrm{I}_{\mathrm{b}}=$ the design of current of circuit, $\mathrm{I}_{\mathrm{t}}=$ the value of current for ingle circuit at ambient temperature. For cables installed above ground $\mathrm{C}_{\mathrm{s}}$ and $\mathrm{C}_{\mathrm{d}}=1$.

\section{For group}

$$
I_{t} \geq \frac{1}{C_{a} C_{s} C_{d} C_{i}} \sqrt{\left(\frac{I_{n}}{C_{f} C_{c}}\right)^{2}+0.48 I_{b}{ }^{2}\left(\frac{1-C_{g}{ }^{2}}{C_{g}^{2}}\right)}
$$

For cables having cross sectional area $16 \mathrm{~mm}^{2}$ or less, the design value of $\mathrm{mV} / \mathrm{A} / \mathrm{m}$ is obtained by multiplying the tabulated value by factor $\mathrm{C}_{\mathrm{t}}$ given by:

$$
\mathrm{C}_{\mathrm{t}}=\frac{230+\mathrm{t}_{\mathrm{p}}-\left(\mathrm{C}_{\mathrm{a}}{ }^{2} \mathrm{C}_{\mathrm{g}}{ }^{2} \mathrm{C}_{\mathrm{s}}{ }^{2} \mathrm{C}_{\mathrm{d}}{ }^{2}-\frac{\mathrm{I}_{\mathrm{b}}{ }^{2}}{\mathrm{I}_{\mathrm{t}}{ }^{2}}\right)\left(\mathrm{t}_{\mathrm{p}}-30\right)}{230+\mathrm{t}_{\mathrm{p}}}
$$

\section{For AC three phase system}

$$
F_{b o}=\frac{\sqrt{3} I\left(R_{c} \cos 0+X_{c} \sin \delta\right) L}{1000}
$$

Where $\mathrm{V}_{3 \varnothing}$ is the three phase voltage drop (V), I is the nominal full load or starting current as applicable (A), $R_{c}$ is the ac resistance of the cable $(\Omega / \mathrm{km}), X_{c}$ is the ac reactance of the cable $(\Omega / \mathrm{km}) \cos \varnothing$ is the load power factor (pu) $\mathrm{L}$ is the length of the cable $(\mathrm{m})$ [7]. 


\section{For AC single phase system}

$$
I_{1 e}=\frac{2 I\left(R_{e} \cos \phi+X_{e} \sin \phi\right) L}{1000}
$$

It is standards to indicate maximum permissible voltage drops, which is the maximum voltage drop that is permissible across a cable. If the cable exceeds this voltage drop, then a bigger cable size should be preferred.

Greatest voltage drops across a cable are specified because load consumers will have an input voltage tolerance range. If the voltage at the electrical device is lower than its rated minimum voltage, then the appliance may not work appropriately [8].

It may be more precise to calculate the maximum length of a cable for a particular conductor size given a maximum permissible voltage drop $5 \%$ of nominal voltage at full load rather than the voltage drop itself. To construct tables showing the maximum lengths corresponding to different cable sizes in order to speed up the selection of similar type cables.

\section{For a three phase system}

$$
L_{\mathrm{max}}=\frac{1000 \mathrm{i} \delta}{\sqrt{3} I\left(R_{c} \cos \varphi+\boldsymbol{X}_{c} \sin \phi\right)}
$$

\section{For a single phase system}

Table 3. Shows the percentage of low voltage installation supplied voltage

\begin{tabular}{lcc}
\hline & Lighting & Other Uses \\
\hline $\begin{array}{l}\text { Low voltage installation supplied } \\
\text { directly from a public low voltage }\end{array}$ & $3 \%$ & $5 \%$ \\
$\begin{array}{l}\text { distribution system } \\
\text { Low voltage installation supplied } \\
\text { from private LV supply }(*)\end{array}$ & $6 \%$ & $8 \%$ \\
\hline
\end{tabular}

$$
L_{\text {max }}=\frac{1000 T_{L o}}{2 I\left(R_{c} \cos \phi+K_{c} \sin \phi\right)}
$$

A high amount of current will flow through a cable for a short time when there is short circuit happens in the circuit. This surge in current flow causes a temperature rise within the cable.

High temperatures can trigger unnecessary reactions in the cable insulation, sheath materials and other components, which can degrade the condition of the cable. Bigger cable cross-sectional area can dissipate higher fault currents. Therefore, cables should be sized to withstand the largest short circuit.

The minimum cable size due to short circuit temperature rise is typically calculated with an equation of the form:

$$
A-\frac{\sqrt{i^{2} t}}{k}
$$

The temperature rise constant is calculated based on the material properties of the conductor and the initial and final conductor temperatures as per equation 12 .

$$
k=226 \sqrt{\ln \left(1+\frac{\theta_{f}-\theta i}{234.5+\theta_{i}}\right)}
$$


Figure 2 shows rating factors to be included for more than one circuit and cables buried directly in the ground with cable- to cable clearance $(\alpha)$.
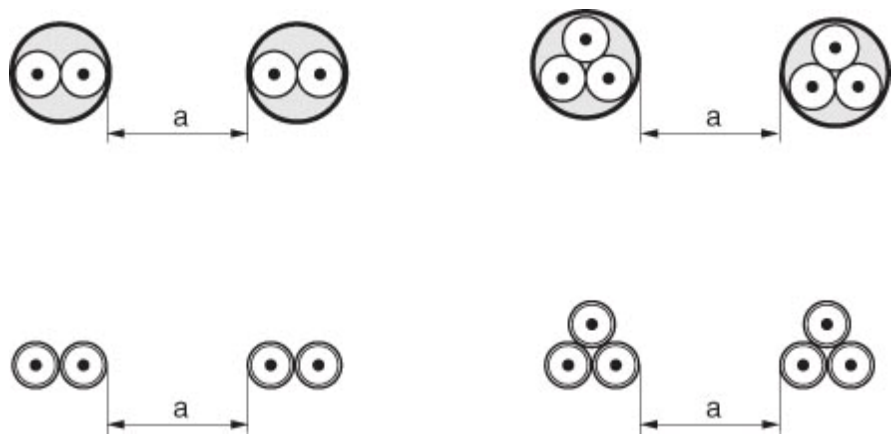

Figure 2. Reduction factors for more than one circuit, single-core or multi-core cables laid directly in the ground.

\section{RESULTS}

Table 4. Voltage drop for different Electrical Components

\begin{tabular}{cccccc}
\hline $\begin{array}{c}\text { Number of } \\
\text { circuits }\end{array}$ & $\begin{array}{c}\text { Nil (cables } \\
\text { touching) }\end{array}$ & $\begin{array}{c}\text { Cable to cable clearance }(\mathrm{a})^{\mathrm{a}} \\
\text { One cable } \\
\text { diameter }\end{array}$ & $0.125 \mathrm{~m}$ & $0.25 \mathrm{~m}$ & $0.5 \mathrm{~m}$ \\
\hline 2 & 0.75 & 0.80 & 0.85 & 0.90 & 0.90 \\
3 & 0.65 & 0.70 & 0.75 & 0.80 & 0.85 \\
4 & 0.60 & 0.60 & 0.70 & 0.75 & 0.80 \\
5 & 0.55 & 0.55 & 0.65 & 0.70 & 0.80 \\
6 & 0.50 & 0.55 & 0.60 & 0.70 & 0.80 \\
\hline
\end{tabular}

Table 5. Sample of calculation of voltage drop using V=IR

\begin{tabular}{|c|c|c|c|c|c|c|c|c|c|c|c|c|}
\hline \multirow[t]{2}{*}{$\mathrm{NO}$} & \multicolumn{2}{|c|}{ DESCRIPTION } & \multirow{2}{*}{$\begin{array}{c}\text { MAX DIST } \\
\text { (m) }\end{array}$} & \multirow{2}{*}{$\begin{array}{c}\text { POWER } \\
\text { (W) }\end{array}$} & \multirow{2}{*}{$\begin{array}{l}\text { LOAD } \\
\text { (W) }\end{array}$} & \multirow{2}{*}{$\begin{array}{l}\text { VOLT } \\
(\mathrm{V})\end{array}$} & \multirow{2}{*}{$\begin{array}{c}\text { CURRENT } \\
\text { (A) }\end{array}$} & \multirow{2}{*}{$\begin{array}{l}\text { CSA } \\
(\mathrm{mm} 2)\end{array}$} & \multirow{2}{*}{$\mathrm{mV} / \mathrm{A} / \mathrm{m}$} & \multicolumn{2}{|c|}{ DROP } & \multirow[t]{2}{*}{$\begin{array}{c}\text { REMAIN } \\
\text { VOLT }\end{array}$} \\
\hline & FROM & TO & & & & & & & & $(\%)$ & (v) & \\
\hline 1 & DB & Light & 10 & 42 & 84 & 240 & 0.35 & 2.5 & 18 & 0.2 & 0.38 & 239.63 \\
\hline
\end{tabular}

Table 5 explains the voltage drop between the origin of an installation and any load point should be greater than the values in the table below expressed with respect to the value of the nominal voltage of installation. Table 6 shows a sample of calculation method to calculate the voltage drop.

The voltage drop for any particular cable run must be voltage drop does not exceed $2.5 \%$ of the nominal voltage. The nominal voltage drop should be not more than $2.5 \%$ voltage from main switch board to any point of installation.

\section{CONCLUSION}

Selecting power cable and types of cables with the sizing of the conductors for specific applications is a very essential part of the plan of any electrical system. This task that is often performed with a least amount of effort and with minimum reflection for all of the applicable design issues. The consequential catastrophe is that inappropriate selection and sizing can easily amplify the installed cost of a facility while also dropping the reliability of the complete system. This paper highlights on some of the considerations that should be practice for cable selection each and every time. It then suggests the right design tool to calculate and facilitate the selection process without resorting to simplifications. 


\section{Nomenclature}

Parametes and constraints

$\mathrm{I}_{\mathrm{c}}$ : Installed current rating $(\mathrm{A})$

$\mathrm{I}_{\mathrm{b}}$ : Base current rating $(\mathrm{A})$

$\mathrm{K}_{\mathrm{d}}$ : Product of all the derating factors

$\mathrm{I}_{1}$ : Full load current (A)

$\mathrm{I}_{\mathrm{p}}$ : Protective device rating (A)

$\mathrm{C}_{\mathrm{c}}$ : Circuit buried in the ground

$\mathrm{C}_{\mathrm{a}}$ : Ambient temperature

$\mathrm{C}_{\mathrm{s}}$ : Soil resistivity

$\mathrm{C}_{\mathrm{d}}$ : Depth of burial

$\mathrm{C}_{\mathrm{i}}$ : Thermal Insulation

$\mathrm{I}_{\mathrm{t}}$ : The value of current for ingle circuit at ambient temperature

$\mathrm{C}_{\mathrm{f}}$ : Semi-enclosed fuse to BS 3036

$\mathrm{C}_{\mathrm{g}}$ : For grouping

$\mathrm{V}_{3 \varnothing}$ : Three phase voltage drop (V)

I: current $(\mathrm{A})$

$\mathrm{R}_{\mathrm{c}}$ : AC resistance of the cable $(\Omega / \mathrm{km})$

$\mathrm{X}_{\mathrm{c}}$ : AC reactance of the cable $(\Omega / \mathrm{km})$

$\cos \varnothing$ : Load power factor (pu)

L: Length of the cable (m)

A: Short circuit temperature rise

$\mathrm{k}$ : Cable material properties

$\theta_{\mathrm{f}}$ : Final conductor temperature

$\theta_{\mathrm{i}}$ : Initial conductor temperature

$\alpha$ : cable- to cable clearance

\section{REFERENCES}

[1] IEC 60364-5-52, (2009), "Electrical installations in buildings - Part 5-52: Selection and erection of electrical equipment - Wiring systems", is the IEC standard governing cable sizing.

[2] National Electricity Code (NEC)

[3] NFPA 70, (2011), "National Electricity Code", is the equivalent standard for IEC 60364 in North America and includes a section covering cable sizing in Article 300.

[4] BS 7671, (2008), "Requirements for Electrical Installations - IEE Wiring Regulations", is the equivalent standard for IEC 60364 in the United Kingdom.

[5] Research paper of Assessment of the Quality of Cables produced in Nigeria by ADETORO, K. ADEBAYO

[6] Coker AJ, Turner WO, Josephs ZT, (1991). Electrical Wiring. Redwood Press Limited, 12 - 28.

[7] J.R Jancauskas, "Cable sizing avoid shortcut and do it right", IECEC 96 Proceedings of the $31^{\text {st }}$ Inersociety Energy Conversion Engineering Conference IECEC-96, 1996.

[8] Nithiyananthan.K, Elavenil V, (2011), 'CYMGRD Based Effective Earthing Design Model for Substation', International Journal for Computer Applications in Engineering Sciences Asia, Vol. I, No 3, pp. 341-346. 